\title{
Analysis of farm specific risk factors for Campylobacter colonization of broilers in six European countries
}

\author{
H.M. Sommer ${ }^{a, b, *}$, B. Borck Høg ${ }^{b}$, L.S. Larsen ${ }^{b, 1}$, A.I.V. Sørensen ${ }^{b}$, N. Williams ${ }^{c}$, J.Y. Mergac, \\ M. Cerdà-Cuéllar ${ }^{\mathrm{d}}$, S. Urdanetad, R. Dolz ${ }^{\mathrm{d}}$, K. Wieczorek ${ }^{\mathrm{e}}$, J. Osek ${ }^{\mathrm{e}}$, B. David ${ }^{\mathrm{f}}$, \\ M. Hofshagen ${ }^{\mathrm{f}}$, M. Jonsson ${ }^{\mathrm{f}}$, J.A. Wagenaar ${ }^{\mathrm{g}}$, N. Bolder ${ }^{\mathrm{g}}$, H. Rosenquist ${ }^{\mathrm{b}}$ \\ a Division of Data Analysis and Statistics, DTU Compute, Technical University of Denmark, Building 324, DK-2800 Kgs. Lyngby, Denmark \\ ${ }^{\mathrm{b}}$ Division of Risk Assessment and Nutrition, The National Food Institute, Technical University of Denmark, Mørkhøj Bygade 19, DK-2860 Søborg, Denmark \\ ${ }^{\mathrm{c} Z}$ Zoonotic Infections of People, Pigs and Poultry Group, Department of Epidemiology and Population Health, Institute of Infection and Global Health, \\ Leahurst Campus, University of Liverpool, Neston CH64 7TE, UK \\ d Centre de Recerca en Sanitat Animal (CReSA), IRTA, Campus de la Universitat Autònoma de Barcelona, 08193-Bellaterra (Cerdanyola del Vallès), Barcelona, \\ Spain \\ e Department of Hygiene of Food of Animal Origin, National Veterinary Research Instiute, Partyzantow 57, 24-100 Pulawy, Poland \\ ${ }^{\mathrm{f}}$ Norwegian Veterinary Institute, Pb 750 Sentrum, N-0106 Oslo, Norway \\ ${ }^{g}$ Department of Infectious Diseases and Immunology, Faculty of Veterinary Medicine, Utrecht University, PO Box 80.165, 3508 TD Utrecht, The Netherlands
}

\section{A R T I C L E I N F O}

\section{Article history:}

Available online 7 June 2016

\section{Keywords:}

Campylobacter

Risk factors

Multinational

Broilers

Generalized linear model

Climate

\begin{abstract}
A B S T R A C T
This study presents on-farm risk factors for the colonization of broiler flocks with Campylobacter based on comparable data from six European countries: Denmark, the Netherlands, Norway, Poland, Spain, and the UK. The study includes explanatory variables from a large questionnaire concerning production, farm management procedures and farm conditions, climate data on mean temperature, sunshine hours, and precipitation, as well as data on Campylobacter status of broiler flocks. All together the study comprises data from more than 6000 flocks. The data were analysed using a generalized linear model. Due to a large number of parameters, some collinearity and relatively many missing values, the model was analysed by a method using all available cases at each step in the modelling process. The modelling process includes backwards elimination and forward selection. Several approaches were furthermore explored by applying different strategies for categorizing explanatory variables and for selecting and eliminating variables in the model.

Despite national differences in broiler production, common risk factors for Campylobacter colonization of broiler flocks were identified across all six countries. These were generally related to inadequate biosecurity. Identified risk factors were: broiler houses older than 15 years, absence of anterooms and barriers in each house, shared tools between houses, long downtime, and drinker systems with bells or cups. Also, the risk of broiler flocks becoming colonized with Campylobacter was clearly affected by country. In descending order, broiler flocks were more likely to be colonized in Poland, the UK, Spain, the Netherlands, Denmark and Norway due to country specific factors that could not be explained by the identified risk factors or any other variables from the questionnaire. The seasonality observed for prevalence values was described by the monthly mean temperature reported in the study, i.e. the higher the temperature, the higher the prevalence of positive flocks.
\end{abstract}

(c) 2016 Elsevier B.V. All rights reserved.

\section{Introduction}

Many attempts have been made to understand the epidemiology of Campylobacter in broilers in search of effective control

\footnotetext{
* Corresponding author:

E-mail address: helle.m.sommer13@gmail.com (H.M. Sommer).

1 Present address: Statens Serum Institut, 5 Artillerivej, 2300 Copenhagen S, Denmark.
}

measures for preventing Campylobacter colonization of indoor commercial broiler flocks. Campylobacter can be transferred to humans e.g. via broiler meat or via the environment being contaminated by feces from production animals such as for example broilers and cattle and thereby cause campylobacteriosis, which is the most common cause of foodborne gastrointestinal illness in the EU and the rest of the industrialized world (EFSA and ECDC, 2015; WHO, 2012). Studies have shown that the main route of introduction of Campylobacter into broiler flocks is from 
the environment outside the broiler house due to one or more breaches in biosecurity (Adkin et al., 2006; Hald et al., 2000; Lyngstad et al., 2008). Hence, controlling Campylobacter in housed birds is primarily a question of strict management practices with a high level of biosecurity and broiler houses that are closed off to the environment. There are, however, many factors involved in achieving a high level of biosecurity and some are more important than others. The most important risk factors are those, where the risk of carrying Campylobacter into the broiler houses is greatest, for example by contaminated air, shoes, clothes, flies, etc.

Previous work from Northern Europe has shown that housed flocks are significantly more likely to be Campylobacter-positive during the summer period (Jonsson et al., 2012; Jore et al., 2010), when ambient temperatures are high compared with the winter period. This is partly related to increased airborne transmission of Campylobacter due to high airflows into the houses during warm periods (Hald et al., 2008). The bacteria may be present in dust or, more importantly, in insects (Bahrndorff et al., 2013; Hald et al., 2007). Climatic factors may, therefore, partly explain the higher Campylobacter prevalence in flocks in parts of Eastern and Southern EU (EFSA, 2010), where ambient temperatures are higher and where there is a constant requirement for higher airflow through the houses. Given variations in climate and broiler flock prevalence across Europe, we speculated if risk factors for flock colonization were similar or different in Northern, Eastern and Southern Europe. To our knowledge, this has not previously been investigated in one study.

Comprehension and awareness of country specific risk factors can guide the choice of the preventive measures in a country to ensure optimal effect, and thus lead to safer broiler meat production within the country. Identification of common risk factors that are applicable in all EU countries is also vital, given the EU-wide nature of broiler production and marketing and the high incidence of campylobacteriosis across the EU.

The objective of this study was therefore to study on-farm risk factors for the colonization of broiler flocks with Campylobacter based on comparable data from six European countries. Previously, we analyzed risk factors in two Northern European countries (Denmark and Norway) (Høg et al., 2016). In the present study, we expand the risk factor study to also include data from the Netherlands, Poland, Spain and the UK, and we included climate related variables to the list of risk factors. The study was designed to investigate risk factors related to climate, geography and on-farm management practices in housed broiler flocks (the most common type of broiler production in EU (EFSA, 2011). The analysis was based on a method that uses all available cases at each step in the modelling process (backwards elimination and forward selection) (Sommer et al., 2013). For every fifth step of backwards elimination a forward selection was run to include earlier eliminated variables if $p$-values were less than 0.10 .

\section{Materials and methods}

\subsection{Questionnaire, Campylobacter status and climate data}

The farm specific variables were obtained through a standardized questionnaire including 43 questions concerning production, farm management procedures, farm conditions, etc. Further information on the questionnaire can be found in Høg et al. (2011), where the questionnaire is also presented in full. Some questions were excluded due to difficulties in interpretations or too little variation in the responses.

In Denmark and Norway, Campylobacter data for flocks on farms that responded to the questionnaire were obtained through national surveillance programmes (Høg et al., 2016). In Norway, only flocks slaughtered from May to October in 2010 and 2011 were tested for Campylobacter, in total 1400 flocks. In Denmark, full annual datasets were obtained from 2010 and 2011, in total 3864 flocks. Campylobacter flock data from Poland, Spain and the UK were obtained through a two-year longitudinal study within the period 2011-2013, where all flocks in the study houses were tested for Campylobacter. Furthermore, Campylobacter results were obtained from 276 flocks from Poland, 201 flocks from Spain and 219 flocks from the UK. In the Netherlands, Campylobacter status was collected from 221 flocks during 2012 and 2013. All flocks were tested prior to or at the time of catching the first batch of birds from the flock (first thin). All flocks from Denmark, Norway and the Netherlands were sampled on farm by boot swabs and tested using PCR, as described by Lund et al., (2004). In Poland, Spain and the UK, caeca from 10 birds per flock were sampled at the slaughterhouse and pooled before microbial analysis; isolation and confirmation of Campylobacter organisms in caecal contents were undertaken as described in ISO 10272-1:2006. At least one Campylobacter isolate per batch was speciated using phenotypic methods as described in ISO 10272-1:2006 or by PCR as described by Klena et al., (2004).

Climate data were collected from weather stations as close as possible to the farms included in the study. This meant that two-three climate datasets were obtained from Norway, Poland, Spain and the UK. However, due to small country size for Denmark and the Netherlands, only one data set per country was included for these two countries. Climate data were matched to each flock by the month of slaughter. Three climate variables were chosen to represent the climate; monthly outside mean temperature, monthly total precipitation, and monthly total sunshine hours. These three variables were chosen, because a preliminary analysis of the Danish data had shown their ability to describe the seasonality in the broiler flocks prevalence (data not shown).

\subsection{Data preparation}

Questionnaire data were prepared for analysis to improve data quality and to maximize the number of data and variables in the final model. This step was essential for running the model with as many variables as possible. Wherever reasonable, missing values were filled in, and the number of parameters was reduced by merging variables or categories. Furthermore, highly correlated variables were excluded.

\subsubsection{Merging}

To reduce the number of parameters, some of the categories within variables were merged, especially for variables with a large number of categories and many combinations of these. Variables were merged based on expert's opinions and the empirical prevalence estimates. If experts suggested categories to be merged, but the empirical prevalence estimates were largely different, then the categories were not merged. Two questions had a hierarchical structure and were merged in order to avoid collinearity, e.g. the merging of variables concerning downtime between flocks (Using downtime (yes/no) and Duration of downtime). If no downtime, the duration of downtime was set to zero and, thus, became part of the variable Duration of downtime (from now on referred to as Downtime).

\subsubsection{Collinearity}

Correlation between two or more variables (multicollinearity) may cause problems running the model as a consequence of an unsuccessful approximation to the inversed Hessian matrix (Altman et al., 2004). In this study, we removed one of the highly correlated sets of variables from the model initially (to make the model run) and later allowed the removed variables to re-enter the model in the forward selection. 
Table 1

Percentage (\%) of missing values per country and in all countries.

\begin{tabular}{lrrrrrrr}
\hline Variables & DK & ES & NL & $\begin{array}{l}\text { NO } \\
\%\end{array}$ & PL & UK & All countries \\
\hline Rodent control frequency & 11 & 80 & 16 & 23 & 28 & 5 & 21 \\
House surroundings, non-access areas & 3 & 0 & 16 & 27 & 86 & 45 & 20 \\
Time of thinning (to remove the birds) & 72 & 0 & 5 & 89 & 14 & 30 & 68 \\
Time between thinning & 72 & 5 & 5 & 90 & 10 & 45 & 69 \\
Cats access to broiler house & 36 & 90 & 53 & 49 & 76 & 50 & 48 \\
Dogs access to broiler house & 35 & 73 & 35 & 45 & 49 & 27 & 42 \\
\hline
\end{tabular}

\subsubsection{Missing values}

Missing values in the explanatory variables are problematic in statistical analyses. They may obstruct running a model with relative many parameters and affect the conclusions if they occur systematically, which may reduce the representativeness. Furthermore, they imply a loss of information, which often results in less accurate estimates of the parameters. Therefore, missing values were filled out by using information from farmers' remarks in the questionnaire whenever possible and they were tested for systematic missingness. More than $95 \%$ of the data records contained one or more missing values. All variables with $20 \%$ or more missing values were examined for systematic missingness. This was tested according to the variable Country by computing the relative numbers of missing values for each country and applying a chi-square test (Fishers exact test in cases of few observations). Due to multiple chi-square tests, the significant level was adjusted by using the Bonferroni correction (Bonferroni, 1936).

Further on, a few questionnaire variables were excluded due to difficulties in interpreting the answers and some variables had too little variation to be included in the model (Høg et al., 2016).

\subsection{Data analyses}

\subsubsection{Statistical analysis}

The final dataset, which comprised more than 40 variables (climate plus questionnaire variables) from six countries, was analyzed by a multivariable variance analysis. The prevalence, $p_{i, j, k, \ldots}$ was the response variable in the model and was defined as the proportion of Campylobacter positive flocks out of the total number of broiler flocks produced a given month on a given broiler farm. Since the response variable was binomially distributed, a generalized linear model was applied and the response variable was transformed using a logit link function:

$\operatorname{logit}\left(p_{i, j, k, \ldots}\right)=\log \left(\frac{p_{i, j, k, \ldots}}{1-p_{i, j, k, \ldots}}\right)=\beta_{0}+\beta_{1} X_{i}+\ldots+\beta_{4, k}$

where, $p_{i, j, k, \ldots}$ is the prevalence value, $\beta_{1} X_{i}$ express a regression term with temperature, $\beta_{4, k}$ express a categorical term. The number index for the betas $(1,2, \ldots)$ refers to the question number given in Table 1 in Høg et al. (2016).

The analyses were carried out using PROC GENMOD in SAS (version 9.4, SAS Institute Inc.). This routine requires complete-cases data. Since the study consisted of repeated measurements from the same farms (several records from different months), the model was explored for different variance structures and an overdispersion parameter was found suitable.

The next step was to find out which of the groups within a variable that contributed to an increased risk. Predicted population margins were calculated as the means for a balanced design using the LSMEANS statement in SAS.

LSMEANS $=\operatorname{logit}(p p)=\sum_{i=1}^{N} \operatorname{logit}\left(p_{i}\right) \cdot 1 / N$ where $p_{i}$ is the predicted prevalence estimate in a cell (given by the combinations of parameters for the categorical variables), $p p$ is the marginal population estimate, and $N$ is the total number of cells. The equally weighting, when calculating the marginal population means, results in marginal population means that are adjusted for influence of other variables in the model. The regressor variable (temperature) was included in the LSmeans estimations as an overall mean temperature, which balanced out the effect of the temperature between the countries. The adjustment of LSmeans made a direct visual comparison of the effect of the parameters possible. In order to test the differences between the parameter estimates, Tukey's multiple comparison tests were applied.

\subsubsection{Modelling process}

Fig. 1 provides an overview of the modelling process. Before running the actual risk factor analyses, pre-modelling was carried out to determine constants and setup important for modelling seasonality of the Campylobacter prevalence. The risk factor analyses started with an initial model including as many main effects as possible but no interaction terms. The model was then reduced using backward elimination and a forward selection routine as described by Sommer et al. (2013) and reached a reduced model with significant variables. Several approaches for the models were then explored, using different strategies for categorizing the explanatory variables. The reduced model, which comprised the largest possible dataset, was selected as the main model and is referred to as such. Finally, the constants (temperature cutoff and shift) in the pre-model were optimized including the newly identified significant variables and the main model was run again.

A previously published model approach was used (Sommer et al., 2013). In brief, the process of identifying significant variables began with an initial model and stepwise the number of variables was reduced. For every fifth step of backwards elimination a forward selection was run to include previously eliminated variables if $p$-values were less than 0.10 . This procedure allowed the sample base to expand each time a variable with missing values was removed from the model. Insignificant variables were removed using the following principle; the three variables with the highest $p$-values were selected and among these the one with the largest number of missing values was removed.

Variables that were not in the model could enter the model in the forward selections routines if $p$-values were $<0.1$. Interaction terms were included in the model when the number of variables was reduced considerably and thus allowed for inclusion of more variables.

\subsubsection{Modelling seasonality}

The seasonal distribution of Campylobacter prevalence in the broiler flocks, i.e. a higher prevalence during the warmer months and a lower during the colder months of the year, was included in the risk factor analysis. Preferably, the seasonality should be explained by variables in the model instead of a sinus-cosine function, which has been used in other studies (Boysen et al., 2011, Chowdhury et al., 2012). The only variables that varied over the 


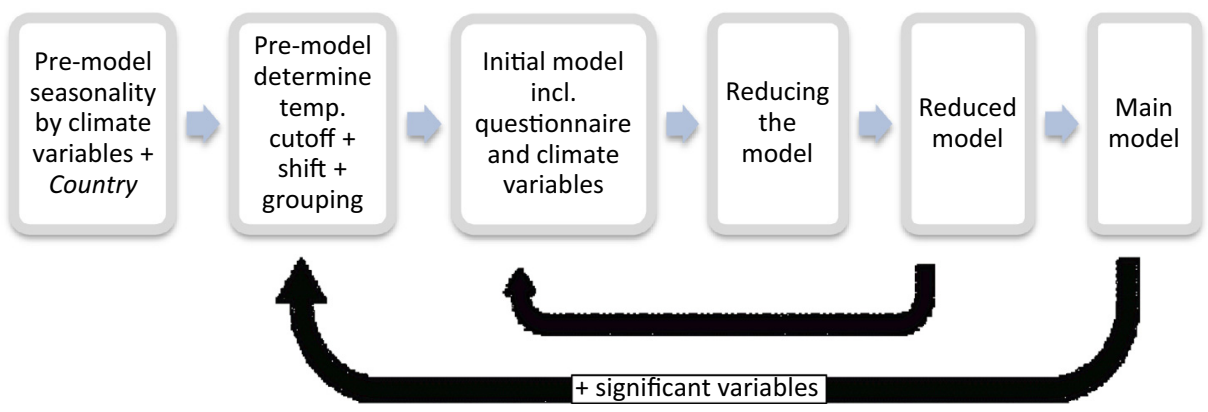

Fig. 1. Modelling flow of the risk factor analyses.

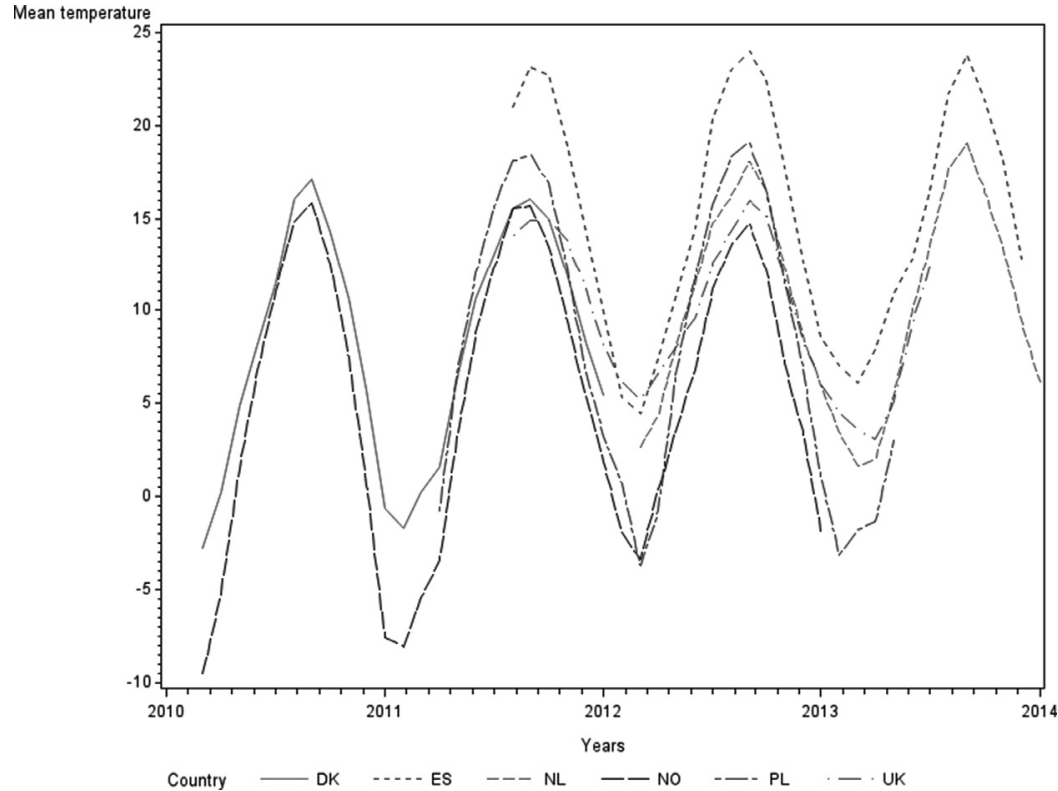

Fig. 2. Seasonality in monthly mean temperatures for six European countries. The temperatures on the y-axis are given as degree Celcius.

months were the climate variables: Temperature (mean temperature for a given month), Sunshine (total sunshine hours for a given month), and Precipitation (total amount of precipitation for a given month). It was therefore explored if these could replace the sinuscosines functions by running different pre- models. Pre-models only containing Country + climate variables were tested. In order to compare the results of the pre-models, the analyses were carried out using the same set of complete data for all pre-models. In Fig. 2, the seasonality in the temperature data from the six countries are shown.

It was examined whether a cutoff for the temperature was necessary, i.e. a value below which the temperature would not affect the broiler flock prevalence significantly. We expected that the Campylobacter prevalence to increase with increasing temperature. Since the climate data were reported for the month of which the chickens were slaughtered and not for the period they were grown, the Temperature was shifted back in time.

$\operatorname{Temp}_{i}=\operatorname{Temp}_{i}^{*}+\left(\right.$ Temp $_{i-1}^{*}-$ Temp $\left._{i}^{*}\right) \cdot{ }^{\prime}$ shift $^{\prime}$

where $\mathrm{Temp}_{i}$ is the temperature variable after the time shift. Temp is the original temperature variable at month $i$ and 'shift' is the number of month shifted back in time. The regressor variable Temp was split into two variables, by the interaction term Temp*EU. The $E U$ variable divided the countries into two groups: (1) Denmark and Norway and (2) the Netherlands, Poland, Spain and the UK. This was necessary since the effect of the regressor variable varied between the two groups, i.e. the temperature had a larger effect on the annual prevalence estimates for Denmark and Norway than for the other countries.

Since the variables in the model may have some effect on the estimate of the cutoff and shift (and vice versa) the model was rerun (the loop back in Fig. 1) after having identified the (first) main model. The cutoff temperature and the magnitude of the time shift were optimized by running the main model again now including different combinations of cutoffs and shifts. The combination that resulted in the smallest Akaike information criterion (AIC) (goodness of fit) value for the model was selected.

\section{Results}

\subsection{Pre-analyses}

Two pairs of variables were highly correlated: Age of newest house and Age of oldest house, and Number of houses and No. of birds slaughtered per year by 0.68 and 0.53 , respectively. One from each pair (Age of newest house and Size of production) were left out from the initial model to enable the model to run.

Six variables had systematically missing values (Table 1 ). Some of these had reasonable explanations; e.g. for the variables Time of thinning and Time between thinning Norway had the largest number of missing values, because a small percentage of the Norwegian farms use thinning. Spain had a large number of missing values for the question Cats access to broiler house, because very few farms reported having cats on the farm. These six variables were not part of the model initially, but were included at a later stage by the forward selection routine if $p$-values were below 0.1 . 


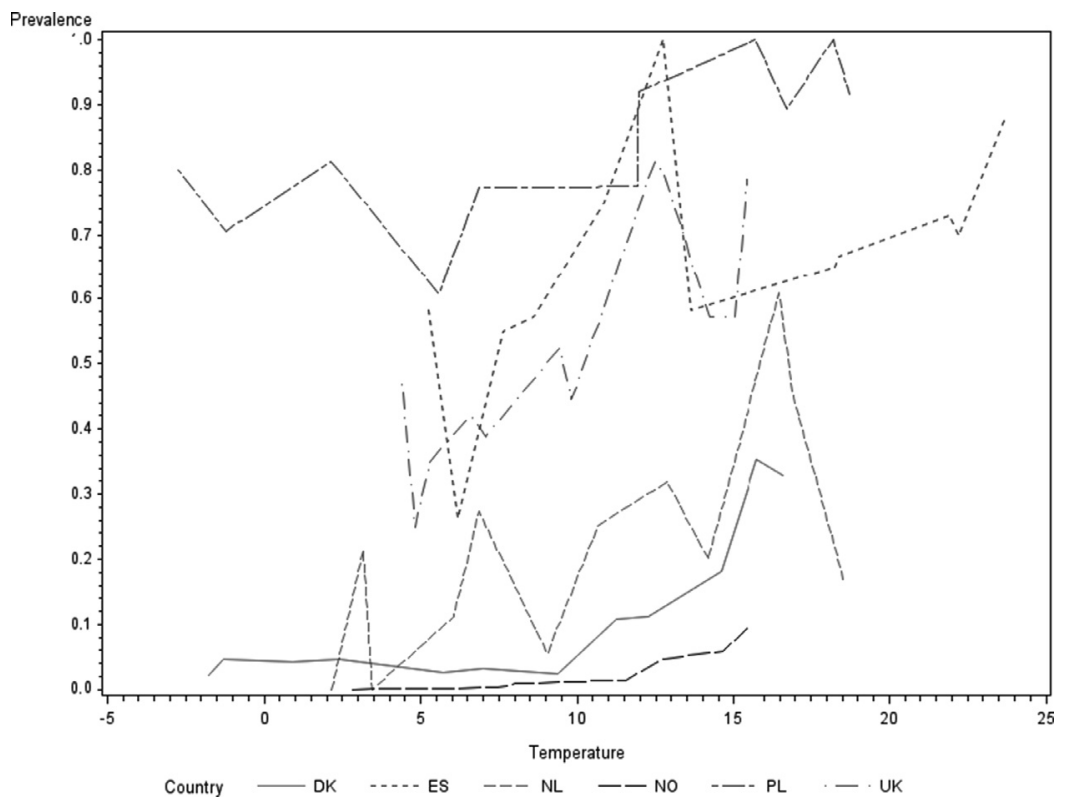

Fig. 3. Mean monthly temperature per country plotted against empirical Campylobacter prevalence values. The temperatures are given in degrees Celcius.

Table 2

Pre-models to examine the fit of seasonality by using climate data. Shift, cutoff, and group are all related to the variable Temperature. AIC is the Akaike's Information Criterion. The smaller AIC the better model fit.

\begin{tabular}{lc}
\hline Pre-models & AIC values \\
\hline i.1 Country, sin, cosines & 2669.3 \\
i.2 Country, Temperature, Sunshine, Precipitation & 2673.5 \\
i.3 Country, Temperature+cutoff, Sunshine, Precipitation & 2672.2 \\
i.4 Country, Temperature+shift+cutoff, Sunshine, Precipitation & 2644.9 \\
i.5 Country, Temperature+shift+cutoff+group, Sunshine, Precipitation & 2610.0 \\
\hline
\end{tabular}

The climate variables described the seasonality better than the sinus-cosine function, i.e. the AIC values for the climate-models i.4 and i.5 were lower than the AIC value for the sinus-cosine model (i.1) (Table 2). In model i.4 Sunshine was not significant and in model i.5 Sunshine and Precipitation were not significant. In other words, Temperature in itself seemed to be able to describe the seasonality in the prevalences. Note that shift is moving the temperature back in time; cutoff defines a temperature for which the variable Temperature does not have any effect if lower than this cutoff value. In Fig. 3, the Campylobacter prevalence $=$ N_positive / N_total per month is plotted against the monthly mean temperature in each of the six countries. In general, the Danish and Norwegian data were used to define an initial cutoff temperature. The variations in data for the other four EU countries were too large to identify a cutoff. 'Groups' were created since Denmark and Norway responded more strongly on the variable Temperature compared to the rest of the six countries - the 'group' indicates an interaction between country groups and Temperature.

Based on the results in Fig. 3 the temperature cutoff was initially set to $10^{\circ} \mathrm{C}$. The models i.3-i.5 were run using this cutoff value (Table 2). The magnitude of the shift was determined by running the model with the variables Country+climate variables for different magnitudes of the shift. The fits were compared by using the AIC values to determine the best initial estimate of the shift which was found to be 0.5 month.

\subsection{Campylobacter prevalence}

The observed prevalence values of Campylobacter in broiler flocks from the participating farms in the six countries are shown
Campylobacter positive flocks

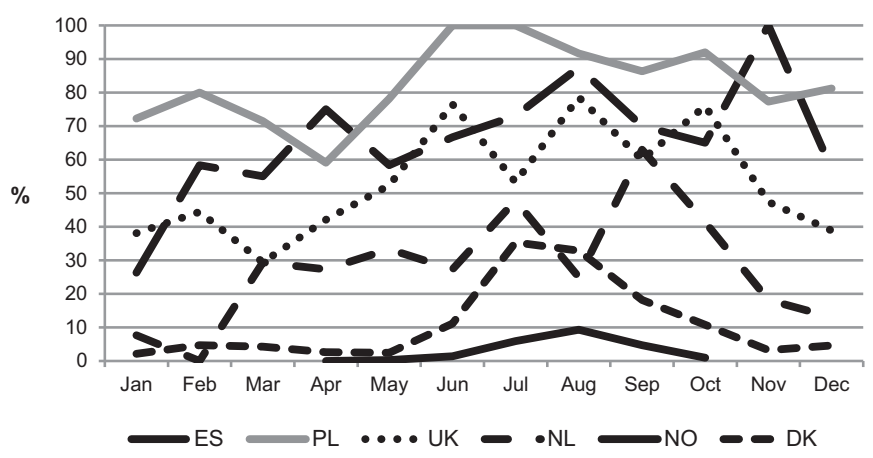

Fig. 4. Observed prevalence of Campylobacter in broiler flocks from participating farms in six European countries. The monthly estimates of the prevalence are calculated from several years.

in Fig. 4. No farms from the study were consistently negative throughout the study period. Almost a third of the participating farms in Poland were tested consistently positive throughout the study period.

A clear seasonal trend was observed for Danish and Norwegian data with a higher prevalence in the warmer months; June-October (Fig. 4). Also for the Dutch data, there was a clear seasonal distribution, with less than $20 \%$ positive flocks from November to February. The seasonal variation was less pronounced in Poland, Spain and the United Kingdom, where the percentage of positive flocks was never below 59\%, $26 \%$ and $29 \%$, respectively.

Differences in the temperature patterns in each country were considered an important explanatory variable to describe the differences in prevalence values between the countries. Therefore, the mean temperature for the data in the study (temperatures above the cutoff value) for each country were calculated and depictured against the prevalence values. However, there was no unique association between mean temperature in the individual countries and the prevalence (Fig. 5). Especially Poland and the UK had higher prevalence values than expected if the mean temperature was the most important risk factor. Hence, the temperatures explained the seasonality well but could not completely explain the prevalence differences between the countries. 


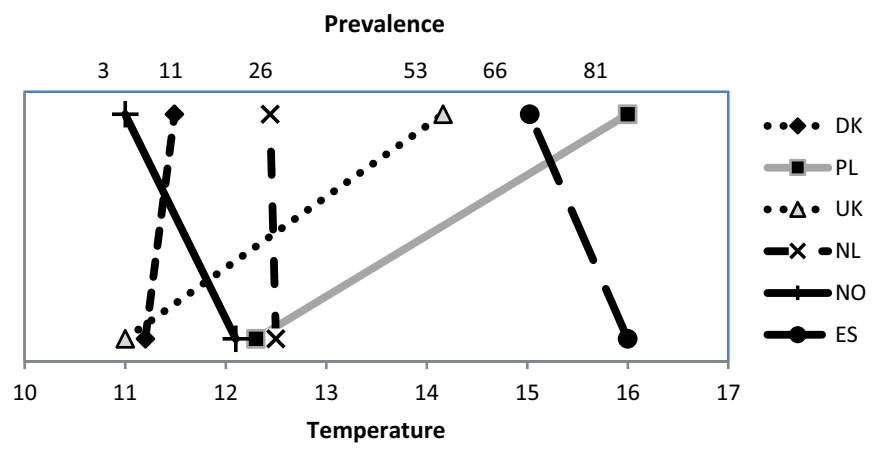

Fig. 5. Relation between mean temperature and mean Campylobacter prevalence. The mean temperature was calculated from the study data temperature above the cutoff value of $8^{\circ} \mathrm{C}$. Data for Norway only included the summer period (MayOctober 2012, 2013).

\subsection{Data and variables}

The initial models included 34 variables and contained $67 \%$ of the full data set. This was the largest number of variables for which the models could run. Some variables had a low $p$-value $<0.10$ throughout the analyses, while others had low $p$-values only towards the end of the model reduction process, yet others went (out and re-entered) into the model by the forward selection routine. Six variables were permanently excluded from the model due to too little variations in the variable, difficulties in interpretation, or inclusion in other variables. Furthermore, variables with $20 \%$ or more missing values were left out from the initial model (Rodent control frequency, Thinning time, Time between thinning, Reverse ventilation, Dogs access to house, Cats access to house), as well as two highly correlated variables Age of newest house (correlated with Age of oldest house) and No. of birds slaughtered per year (correlated with No. of broiler houses). Having identified the first main model, the model was re-run in order to optimize the cutoff and shift estimates. In Table 3 the different combinations of cutoffs and shifts together with the AIC values are shown. The combination of cutoff and shifts that had the smallest AIC value was a cutoff of $8^{\circ} \mathrm{C}$ and a shift of 15 days. The model was re-run again from the beginning with the new values of cutoff and shift. The second main model resulted in the same variables as the first and the estimated $p$-values were almost the same as in the first main model (only a few changes on the fourth decimal). This was the final model.

\subsection{Results for the main model}

The final model was based on $95 \%$ of the full dataset and 11 significant variables. These are shown in Table 4 along with their $p$-values, estimates, and the standard errors (SE). Some farms delivered more than one flock in a given month, which explains that the total number of flocks is greater than the total number of data/record lines in the final model.

The mean temperature described the seasonality very well. Shifting the mean temperature 15 days back and using a cutoff of the temperature of $8^{\circ} \mathrm{C}$ displayed the best fit of the data. Moreover, nine factors were found to have a significant effect on the risk of flocks becoming colonized with Campylobacter: Country, Age of house, Anteroom+barrier, Downtime, Drinkers, Tools, Age of house $*$ Country, Age of house $*$ Anteroom+barrier, Age of house $*$ Tools. The interaction term Age of house*Country indicates that the effect of Age of house depends on the country. Furthermore, the last two interaction terms showed that the effect of Anteroom+barrier and Tools depend on Age of house.
Table 3

Optimization of temperature cutoff and temperature shift. The main model (on the second loop) was modelled with different values of cutoff and shift. AIC is the Akaike's Information Criterion. The smaller AIC the better model fit.

\begin{tabular}{|c|c|c|c|c|c|}
\hline \multirow[b]{2}{*}{ AIC-values } & \multicolumn{5}{|c|}{ Temperature cutoff } \\
\hline & & $7^{\circ} \mathrm{C}$ & $8^{\circ} \mathrm{C}$ & $9^{\circ} \mathrm{C}$ & $10^{\circ} \mathrm{C}$ \\
\hline \multirow{3}{*}{$\begin{array}{l}\text { Temperature } \\
\text { shift }\end{array}$} & -12 days & 2988.2 & 2986.9 & 2992.6 & 3006.7 \\
\hline & -15 days & 2985.7 & 2985.3 & 2989.9 & 3003.8 \\
\hline & -18 days & 2989.8 & 2989.5 & 2994.2 & 3007.3 \\
\hline
\end{tabular}

In Fig. 6, the marginal population means (LSmeans estimates) are shown together with the $95 \%$ confidence intervals for all the variables in the final model. On the y-axes the logit of the LSmean values are given - the higher the values the higher the prevalence of Campylobacter. The LSmean values should not be interpreted directly, since it is a value on the logit scale and since it is calculated for a balanced design (unlike our study). The LSmean values only serve to compare the effect estimates for the levels within a variable. For the variable Country (Fig. 6h), Denmark and Norway had significantly lower values and Poland significantly higher value than the other countries. The UK, the Netherlands and Spain were not significantly different from each other (tested by the Tukey multiple comparison test).

In general, farms where the newest broiler houses were less than five years old (Age of house) had a significantly lower risk of becoming infected by Campylobacter than those with older houses (Fig. 6a). There were no significant differences between the two last categories (years 6-15 and >15). However, when taking a more detailed look at the effect per country, a different trend was observed for Poland, where flocks on the farms with the oldest houses had a lower risk of becoming colonized with Campylobacter (Fig. 6i).

Having both anteroom and barrier (Anteroom+barrier) as well as designated tools (Tools) in all the houses on the farm generally led to significantly lower risk than if these biosecurity measures were not in place in all houses (Fig. 6c and 6d). Designated tools implies that all tools e.g. brooms and shovels, were exclusively used in one broiler house, and not transferred from one house to another. However, when more information was provided, it became clear that the effects of Anteroom+barrier and Tools were related to the age of the house, and actually had no effect in the oldest houses (Fig. $6 \mathrm{f}$ and 6g). Downtime was significant; the longer the downtime the higher the risk of flocks becoming colonized (Fig. 6e). Downtime $<10$ days had a significantly lower risk than category downtime $>10$ days. Also the type of drinker systems appeared to affect the risk, i.e. drinker nipples without cups were associated with the lowest risk (Fig. 6b). The risk estimates for drinker nipples with cups or bells were not significantly different from each other.

\subsection{Nearly significant variables}

Some variables were close to entering the final model. Rodent control frequency was in fact significant, but was left out due to many missing values and systematic missingness. Carrying out rodent control less than four times a year increased the risk. Water supply was very close to being significant with a municipal water source as the best, followed by private bore holes and surface water. The Fly screen variable was just significant $(\mathrm{p}=0.048)$; having screened the house as the best, but since only three Danish farms had fly screens, it was left out from the final model. Reverse fans was also significant, but with $35 \%$ missing values it was also left out. 

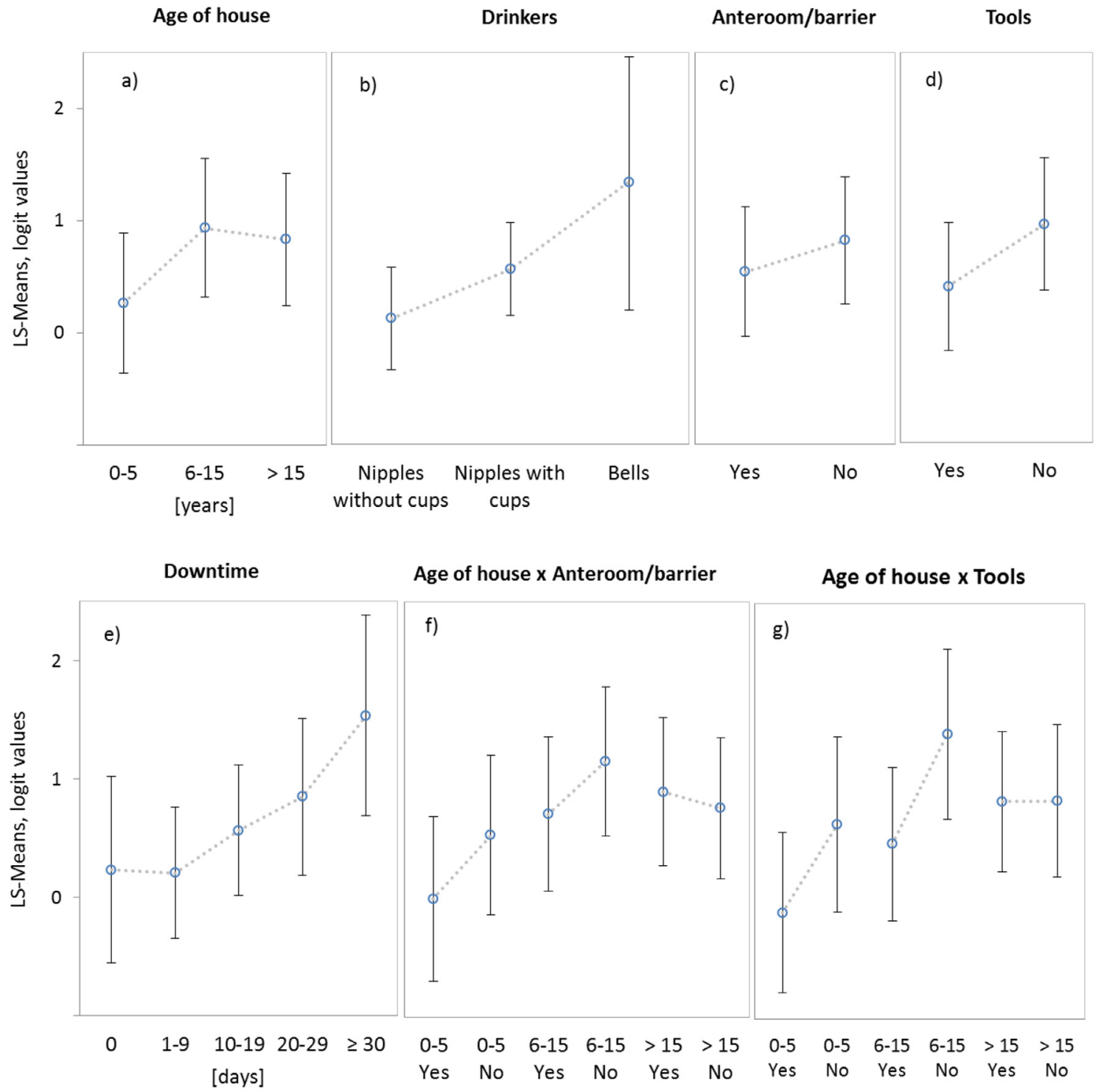

Country

Country x Age of house

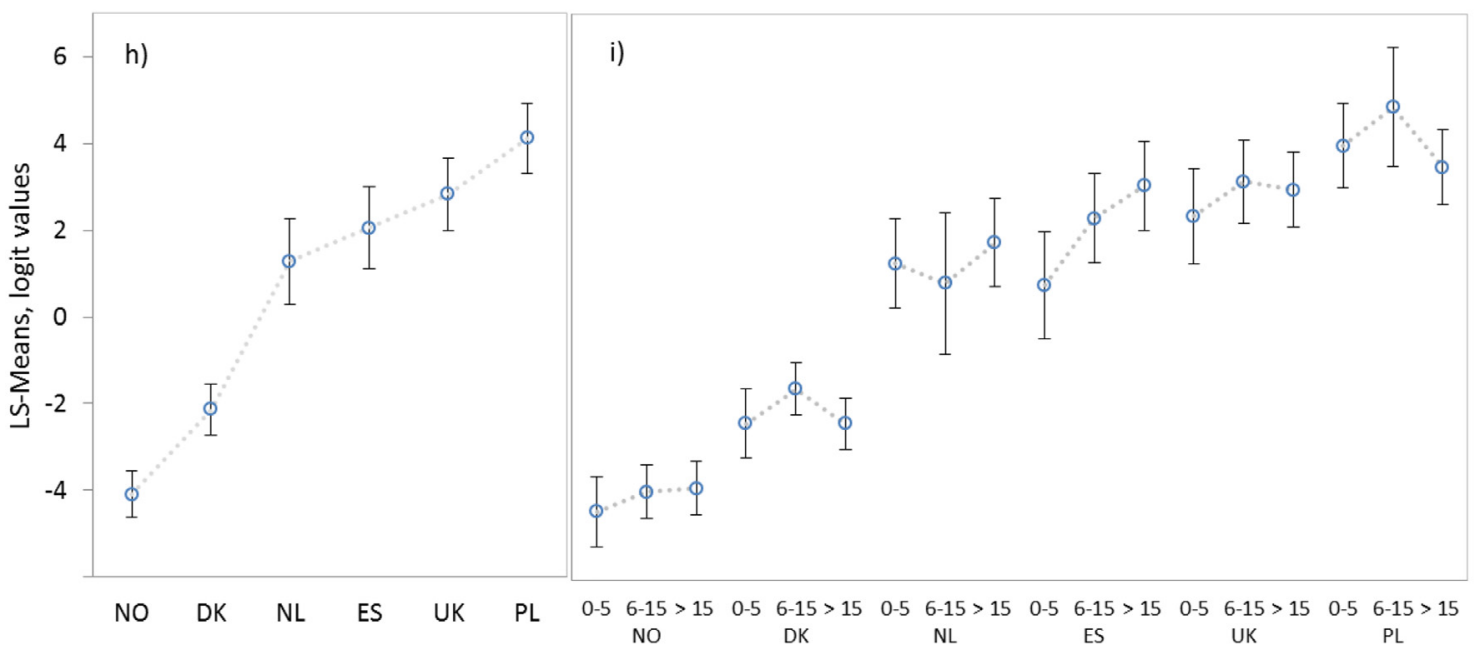

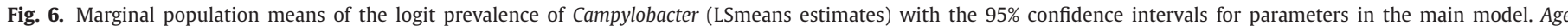

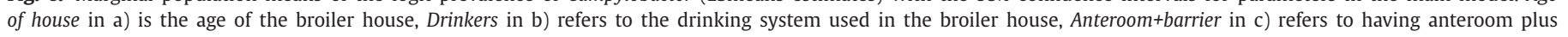

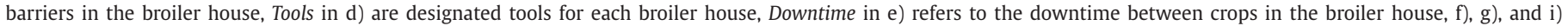
are interaction terms. 
Table 4

Significant variables in the final model of risk factors for broilers becoming Campylobacter positive in six European countries.

\begin{tabular}{|c|c|c|c|c|c|c|}
\hline Parameter & Variables & $p$-value & Category & & Estimate & SE \\
\hline$\beta_{0}$ & Intercept & - & & & 0.67 & 0.80 \\
\hline$\beta_{1}$ & Temp * & $<0.001$ & & & 0.15 & 0.03 \\
\hline \multirow[t]{2}{*}{$\beta_{2}$} & \multirow[t]{2}{*}{ Temp $\times E U *$} & \multirow[t]{2}{*}{$<0.001$} & \multirow{2}{*}{\multicolumn{2}{|c|}{$\begin{array}{l}\text { Denmark, Norway } \\
\text { Spain, the Netherlands, Poland, UK }\end{array}$}} & 0.21 & 0.03 \\
\hline & & & & & 0 & 0 \\
\hline \multirow{6}{*}{$\beta_{3}$} & \multirow[t]{6}{*}{ Country * } & \multirow[t]{6}{*}{$<0.001$} & Denmark & & -5.38 & 0.48 \\
\hline & & & Spain & & 0.08 & 0.42 \\
\hline & & & the Netherlands & & -1.22 & 0.40 \\
\hline & & & Norge & & -6.85 & 0.54 \\
\hline & & & Poland & & 0.51 & 0.37 \\
\hline & & & UK & & 0 & 0 \\
\hline \multirow[t]{3}{*}{$\beta_{4}$} & \multirow[t]{3}{*}{ Age of house * } & \multirow[t]{3}{*}{0.002} & $<5$ years & & 0.1 & 0.52 \\
\hline & & & $6-15$ years & & 0.94 & 0.41 \\
\hline & & & $>15$ years & & 0 & 0 \\
\hline \multirow[t]{2}{*}{$\beta_{5}$} & \multirow[t]{2}{*}{ Anteroom+barrier } & \multirow[t]{2}{*}{0.022} & Yes & & 0.14 & 0.17 \\
\hline & & & No & & 0 & 0 \\
\hline \multirow[t]{2}{*}{$\beta_{6}$} & \multirow[t]{2}{*}{ Tools ** } & \multirow[t]{2}{*}{0.001} & Yes & & -0.01 & 0.19 \\
\hline & & & No & & 0 & 0 \\
\hline \multirow[t]{5}{*}{$\beta_{7}$} & Downtime * & 0.006 & 0 days & & -1.3 & 0.46 \\
\hline & & & 1-9 days & & -1.33 & 0.37 \\
\hline & & & 10-19 days & & -0.97 & 0.34 \\
\hline & & & 20-29 days & & -0.69 & 0.35 \\
\hline & & & $>29$ days & & 0 & 0 \\
\hline$\beta_{8}$ & Drinkers & 0.001 & Nippels without cups & & -1.22 & 0.61 \\
\hline & & & Nippels with cups & & -0.78 & 0.61 \\
\hline & & & Bells & & 0 & 0 \\
\hline$\beta_{9}$ & Age of house $x$ Country & 0.001 & Denmark & $0-5$ years & 0.62 & 0.55 \\
\hline & & & & $6-15$ years & 0.62 & 0.45 \\
\hline & & & & $>15$ years & 0 & 0 \\
\hline & & & Spain & $0-5$ years & -1.67 & 0.70 \\
\hline & & & & $6-15$ years & -0.92 & 0.60 \\
\hline & & & & $>15$ years & 0 & 0 \\
\hline & & & the Netherlands & $0-5$ years & 0.13 & 0.63 \\
\hline & & & & $6-15$ years & -1.12 & 0.87 \\
\hline & & & & $>15$ years & 0 & 0 \\
\hline & & & Norway & $0-5$ years & 0.07 & 0.60 \\
\hline & & & & $6-15$ years & -0.27 & 0.50 \\
\hline & & & & $>15$ years & 0 & 0 \\
\hline & & & Poland & $0-5$ years & 1.11 & 0.62 \\
\hline & & & & $6-15$ years & 1.2 & 0.81 \\
\hline & & & & $>15$ years & 0 & 0 \\
\hline & & & UK & $0-5$ years & 0 & 0 \\
\hline & & & & $6-15$ years & 0 & 0 \\
\hline & & & & $>15$ years & 0 & 0 \\
\hline$\beta_{10}$ & Age of house $x$ Anteroom+barrier & 0.019 & Yes & $0-5$ years & -0.67 & 0.32 \\
\hline & & & & $6-15$ years & -0.58 & 0.24 \\
\hline & & & & $>15$ years & 0 & 0 \\
\hline & & & No & $0-5$ years & 0 & 0 \\
\hline & & & & $6-15$ years & 0 & 0 \\
\hline & & & & $>15$ years & 0 & 0 \\
\hline$\beta_{11}$ & Age of house $x$ Tools & 0.013 & Yes & $0-5$ years & -0.74 & 0.38 \\
\hline & & & & $6-15$ years & -0.92 & 0.35 \\
\hline & & & & $>15$ years & 0 & 0 \\
\hline & & & No & $0-5$ years & 0 & 0 \\
\hline & & & & $6-15$ years & 0 & 0 \\
\hline & & & & $>15$ years & 0 & 0 \\
\hline No. of obs. (record lines) & 3.986 & & & & & \\
\hline No. of flocks & 6.042 & & & & & \\
\hline
\end{tabular}

Note: The significance values (type $3 p$-values) and estimates are also given. ${ }^{*}$ denotes that the $p$-values were $<0.10$ all the way through the modelling process. ** denotes that the variable (re-)entered the model in a forward selection step. The categories with the estimated value 'zero', are reference categories.

\section{Discussion}

\subsection{Method used}

Analyzing data from large surveys can be challenging due to a large number of explanatory variables, and often also a large number of incomplete data records. Data records are said to be incomplete if there is missing values for any of the explanatory variables in the model. Most multivariable statistical routines require complete-cases. Thus, when the number of variables is large, the loss in efficiency can be particularly large if the dataset contains missing values (Little and Rubin, 2002). However, if only the dataset of complete cases are included in the analysis, there is loss of statistical power of the tests due to the decrease in effective sample size. Little and Rubin (2002) presented an available-case method, based on the univariate analyses and includes all available cases, where the variable of interest is present. The method involves estimation of all pairwise covariances between parameter estimates. The advantage of this method is that it makes use of all the available data. The disadvantage is that when variables are 
highly correlated, this is not accounted for in the model (Pigott, 2001). The complete-case method is superior to the available-case method, when the correlation is high. Neither method, however, is overall satisfactory. In the present study, we applied a method based on all available cases at each step in the modelling process (backwards elimination + forward selection) (Sommer et al., 2013).

The preparation of the dataset was an essential step, because it allowed us to include more information in the analyses, than if data had not been prepared. Had we not prepared the data and only used complete cases in the model, as little as $4.5 \%$ of the dataset would have been included in the model. However, after preparing the data we were able to use $67 \%$ of the dataset, and by applying the backward elimination and forward selection as described in the present study, we were able to use $95 \%$ of the data in the final model. Many risk factor analyses use only completecases observations throughout the modelling process missing out information in the dataset (Arsenault et al., 2006). The idea behind the forward selection routines was to avoid exclusion of variables in the early steps simply due to a relatively small sample base. These variables were continuously tested for inclusion in the model in later steps by the forward selection procedure.

The collinearity problem could have been solved by implementing ridge regression. However, we chose not to use this method since it introduces bias in the estimates, and since collinearity does not reduce the predictive power or the reliability of the model (Voss, 2004; Belsley, 1991). The collinearity may, however, prevent the model from running, but we solved that as described earlier by reducing the number of missing values and merging categories.

For models with no interaction terms and no continuously variables it is not necessary to estimate the LSmean values in order to compare the effect from the different categories of the risk factors. In such cases, the effects can be read directly from the parameter estimates. However, for models including interaction terms there is an advantage in estimating the LSmean values in order to compare the levels (Cai, 2014).

\subsection{Significant variables}

Two climate related variables (temperature shift and temperature cutoff) were found to have the optimal values of 15 days and $8^{\circ} \mathrm{C}$, respectively. In comparison, Patrick and co-workers (2004) found a shift (delay) of 3 weeks to be the optimal value, when mean temperature was used to describe the seasonality in the prevalence values for Campylobacter in broiler flock in Denmark. At mean temperatures above $8^{\circ} \mathrm{C}$, they reported a large increase in broiler flock prevalence with increasing temperature. Other studies have defined cutoff values of $6^{\circ} \mathrm{C}$ in Norway (Jonsson et al., 2012).

Most of the risk factors identified in the final model seem reasonable with plausible explanations: Campylobacter prevalence in broiler flocks increases with increasing Age of house (old houses become less 'biosecure' ), absence of Anteroom+barrier (no effective biosecurity at the entrance of the houses), absence of designated Tools (easy cross contamination between broiler houses), and Drinkers with cups (providing a water reservoir where bacteria may grow). Several of these risk factors have also been identified in other studier (Adkin et al., 2006), however in this study, as something new, we have also proven that designated tools and anteroom+barriers only have an effect in new/newer houses and no effect in old houses.

However, a few variables need further explanation. Downtime is one such variable. In this study, as reported by Høg et al. (2016), we found increasing prevalence with increasing downtime. Other studies have found that shorter downtimes (less than 9-14 days) are associated with increased risk (Berndtson et al., 1996; Hald et al., 2000; Lyngstad et al., 2008). However, the ratio of farm- ers that reported not cleaning the house between flocks increased from $0 \%$ to $24 \%$ as the length of the downtime increased. Moreover, the frequency of poor rodent control (1-3 times a year) increased from $0 \%$ to $9 \%$ as the downtime period increased. Furthermore, in Spain, the farms that did not perform as well (possibly with a higher risk of having Campylobacter) as other farms, were less often selected to produce broilers when the demand for broilers was low. For Spain, this partly explains the association between a long downtime and a high prevalence.

Country is another variable that needs explanation. The final model consists of several significant variables that describe the variation in the data. If the variable Country was not significant, the variation seen between the countries could be explained by the rest of the significant variables in the model. However, Country was significant (Table 4), which implies that neither temperature, nor old houses or the lack of designated tools etc. could explain all differences between countries. Some of the differences in prevalence levels between the countries may also be explained by the different sampling and testing schemes applied. Prevalence data from Denmark, Norway and the Netherlands were based on sock samples, whereas data from Spain, Poland, and the UK were based on cloacal swab samples. Sock samples are typically collected 7 to 10 days before slaughter while caecal samples are collected at the time of slaughter. Chowdhury et al. (2012) reported that the prevalence level decreased 9 percentage points from 23\% for the years $2007-2009$ to $14 \%$ for 2010 . The differences between the sampling methods may be due to sock samples being less sensitive and/or to the extended time at risk before the cloacal swab samples are collected compared to the time at which the sock samples are collected. However, even when the differences in the sampling method are taken into account, there is still more variation between the countries than what could be explained by the variables in the model. The reason for this could be that some important factors which vary between the countries were not included in the study, or that the questions in the questionnaire may have been perceived in slightly different ways in the different countries, thereby introducing bias.

The interaction term $T e m p * E U$ was significant. The reason for the differences in the effect of temperature between DenmarkNorway and the other countries could be that many other variables, known or unknown, have a relatively large impact on the Campylobacter prevalence for Spain, the Netherlands, Poland, and the UK and thereby weakens the relative effect of the temperature.

Thinning, where machines and staff enter the broiler house to catch part of the flock for slaughter, has been shown to be a risk factor (Berndtson et al., 1996; Hald et al., 2000) and it was also included as a variable (obtained from the questionnaire) in the present study. However, from several countries we only obtained Campylobacter status data collected before the first batch of broilers from a flock was slaughtered, and could therefore not analyze the effect of this practice.

\subsection{Alternative model approaches}

Other model approaches were tested to explore alternatives for categorizing the outcomes of some of the variables and including/excluding variables with a large number of missing values. Many of these alternative models found more or less the same significant variables as the main model. Two models, however, had slightly different results. One model did not include Age of house $*$ Country and Age of house $*$ Tools in the reduced model, but identified three other variables: No. of houses*Country, Water supply, and Rodent control frequency: This alternative model was based on 3179 records, which were 807 records less than the main model. The variable No. of houses was modeled as a binary variable in the alternative model (categories: one broiler house versus two 
and more broiler houses), rather than as a continuous variable (as in the main model). Having two or more houses increased the risk of introducing Campylobacter into a flock in Norway and Poland, whereas no difference was observed in Denmark, the Netherlands, and Spain. The UK had only farms with two or more broiler houses. For the variable Rodent control frequency the category with the least frequent rodent control ( $<3$ times a year) had a higher risk of introducing Campylobacter than those with more frequent rodent control (4-10 and 11-52 times a year). There were, however, not many observations with $<3$ times a year. The Water supply showed an increased risk if farmers used surface water compared with private bore holes and municipal. Only Norway and Spain had a few farms (less than five out of 173 and 20 respectively) that used surface water and therefore the categories 'private bore holes' and 'surface water' were merged in the main model.

An alternative model was reached based on the reduced model described above. We continued the modelling process after having removed the Rodent control frequency since this variable had a large number of (systematic) missing values (20\% of the data). The alternative reduced model was very similar to the main model except that Rodent control frequency was out and instead Age of house $*$ Country and Age of house $*$ Tools were in the model. This alternative reduced model was now based on 3975 records, only 11 records away from the main model.

Since Norway did not have prevalence data for the winter period, we examined the effect of not including Norway in the common EU model. This resulted in the same significant variables, only the $p$-values changed slightly. The number of data decreased from 3986 to 2355 data records. Hence, including Norway in the model did not bias the results even though the sampling period for Norway only covered the 'summer' period (from May to October).

\subsection{Comparison with results from other studies}

When comparing results from Denmark and Norway (Høg et al., 2016) with the results presented in this study, which includes data from more countries as well as climate data, we identified many of the same significant variables. The study of Danish and Norwegian data, found four more significant variables: No. of houses*Country, Stocking density*Country, Boot dip, and Water supply. These variables and their interaction terms with Country were, however, not significant in the main model in the present study. Boot dip is a disinfecting bath at the broiler house entrance, where staff can dip and disinfect boots prior to entering the house. In Denmark the risk of Campylobacter decreased on farms without boot dip, whereas in the Netherlands and Norway there was no effect. Spain, Poland, and the UK had only one type of response all farms used boot dip. All together, these facts likely caused Boot dip to be insignificant in the present study. The variable Water supply was very close to being significant, with the highest risk estimate for farms using surface water or private bore holes. If the number of houses were broken down as the binary variable described earlier the variable No. of house*Country was significant in one of the alternative models. As in the work of Høg et al. (2016), Norway had an increased risk for farms having two or more broiler houses whereas Denmark did not. In the present study, Poland had an increased risk with more houses, but this was not the case for the Netherlands, the UK, and Spain. Furthermore, the present study identified Tools and three interaction terms Age of house*Country, Age of house*Anteroom+barrier, and Age of house $*$ Tools to be significant risk factors.

A previous Danish study with data from 1999-2000 identified the risk factors: Age of house, Rodent control, Age of chicken when introducing whole wheat, Age of chicken at slaughter, Storage of wheat, No. of chimneys, No. of broiler houses, and Density of cattle farms in the area (Sommer et al., 2013). However, many of the variables in the two models are different, which make comparison of the studies difficult. Nevertheless, some of the variables were alike and were identified in both studies such as Age of broiler house, Rodent control, and No. of houses. Variables concerning the use of wheat in the feed, no. of chimneys in the broiler houses, and presence of cattle farms were not part of the present study and could therefore not be identified as risk factors. No. of chimneys were interpreted as being related to how open the house was to the environment allowing insects to enter the broiler house. Variables on boot dip, tools, and downtime were not part of the study of Sommer et al. (2013). Variables on drinkers and water supply were, however, included but found not to be significant in the study from 1999-2000. In both studies of Danish broiler farms (data from1999-2000 and 2010-2011) the following variables were found not to be significant: other animals on the farm, ventilation system, surrounding area, and number of persons with access to the broiler house.

Chowdhury et al. (2012) also analyzed Danish broiler farms from the period 2009-2010. In accordance with the Danish studies mentioned above they found that the age of the broiler house and the age of chicken at slaughter to be significant risk factors. However, in contrast to the other Danish studies Chowdhury et al. (2012) also found the number of persons with access to the broiler house to be significant similar to what Guerin et al. (2007a) found. The oldest of the Danish studies identified No. of houses to be significant which was not the case for the later Danish studies. The contamination between houses may have been reduced between the times of the two studies due to increased focus on the biosecurity. Since 2000 a control strategy for Campylobacter in broilers has been implemented on all farms through a quality assurance schemes (Rosenquist et al., 2009).

The risk factors identified in this cross country study resemble risk factors that have previously been published in single country studies. Despite different study designs, many studies have found risk factors associated with the level of biosecurity on the broiler farms and in the broiler houses. Hence, hygiene barriers, no. of houses, season/temperature at the time of rearing, disinfection of boot dips, no. of staff, and other animals on farm or on neighboring farms are all among risk factors that have been identified in other studies (Adkin et al., 2006; Agunos et al., 2014; Ellis-Iversen et al., 2009; Guerin et al., 2007a; Guerin et al., 2007b; Guerin et al., 2008; Hald et al., 2000; Hald et al., 2007; Hansson et al., 2010; Newell et al., 2011). The analyses and results of the many risk factors studies carried out for Campylobacter in broilers have illustrated the complexity of Campylobacter epidemiology and explain why there is no single simple method to prevent the broilers from becoming colonized with Campylobacter. Nonetheless, controlling Campylobacter in indoor conventional broilers is primarily a question of strict management practices with a high level of biosecurity and broiler houses that are closed off to the environment. However, as illustrated by the different studies, there are many factors involved in achieving a high level of biosecurity and some are more important than others (Adkin et al., 2006; Agunos et al., 2014; WHO, 2012).

Messages from the present work to future risk factor studies are: Improve the quality of the data, aim at having representative data with no missing values, use broiler house as the unit of the analysis rather than farm, and add optionally new explanatory variables and skip others. One way to facilitate this would be to carry out a thorough pilot questionnaire survey to test the responses to the drafted questions. Also, using electronic questionnaires that can be answered on-line, would greatly facilitate collecting data for such surveys. 


\section{Conclusion}

In conclusion, we have shown that the involved six countries across Europe share the same risk factors for conventional, indoor broilers becoming colonized by Campylobacter despite differences in their broiler production and climates. Identified risk factors were broiler houses older than 15 years, absence of anterooms and barriers in each house, shared tools between houses, as well as a long downtime and drinker systems with water reservoirs such as bells or cups. All of the identified risk factors were somehow related to inadequate practice of biosecurity on the farms. Hence, maintenance of strict biosecurity in broiler houses will inevitable reduce the Campylobacter prevalence in broilers. However, the broiler flock prevalence was also influenced by temperature and by other, unknown country specific factors.

\section{Acknowledgements}

This research was part of the CamCon project; Campylobacter control - novel approaches in primary poultry production, funded by the European Community's Seventh Framework Programme (FP7/2007-2013) under Grant Agreement no. 244547. The assistance of all participating broiler farmers and companies as well as laboratory staff in all participating countries is gratefully acknowledged, without their contributions, this study could not have been carried out.

\section{References}

Adkin, A., Harnett, E., Jordan, L., Newell, D., Davison, H., 2006. Use of a systematic review to assist the development of Campylobacter control strategies in broilers. J. Appl. Microbiol. 100, 306-315.

Agunos, A., Waddell, L., Léger, D., Taboada, E., 2014. A systematic review characterizing on-farm sources of Campylobacter spp. for broiler chickens. PLoS One 9, e104905.

Altman, M., Gill, J., McDonald, M.P., 2004. Numerical Issues in Statistical Computing for Social Scientist. John Wiley \& Sons, Inc.

Arsenault, J., Letellier, A., Quessy, S., Normand, V., Boullianne, M., 2006. Prevalence and risk factors for Salmonellae spp. and Campylobacter spp. caecal colonization in broiler chicken and turkey flocks slaughtered in Quebec, Canada. Prev. Vet. Med 81, 250-264.

Bahrndorff, S., Gill, C., Lowenberger, C., Skovgård, H., Hald, B., 2013. Musca domestica as a potential vector of Campylobacter jejuni.. In: CHRO13: 17th International workshop on Campylobacter, Helicobacter and related organisms. University of Aberdeen, United Kingdom, p. 151.

Belsley, D., 1991. Conditioning Diagnostics: Collinearity and Weak Data in Regression. Wiley, New York ISBN 0-471-52889-7.

Berndtson, E., Emanuelson, U., Engvall, A., Danielsson-Tham, M.-L., 1996. A 1-year epidemiological study of Campylobacter in 18 Swedish chicken farms. Prev. Vet. Med. 26, 167-185.

Bonferroni, C.E., 1936. Teoria statistica delle classi e calcolo delle probabilitá, Pubblicazioni del R. Instituto Supriore de Scienze Economiche e Commerciali di Firenza 8, 3-62.

Boysen, L., Vigre, H., Rosenquist, H., 2011. Seasonal influence on the prevalence of thermotolerant Campylobacter in retail broiler meat in Denmark, 2011. Food Microbiol. 28, 1028-1032.

Cai, W., Making comparisons fair: how LSmeans unify the analysis of linear models, SAS Institute Inc. Paper SAS060-2014.

Chowdhury, S., Sandberg, M., Themudo, G.E., Ersbøll, A.K., 2012. The effect of presence of infected neighbouring farms for the Campylobacter infection status in Danish broiler farms. Spat Spatiotemporal Epidemiol 3, 311-322.

EFSA and ECDC, 2015. The European Union summary report on trends and sources of zoonoses, zoonotic agents and food-borne outbreaks in 2013. EFSA J. 13 (1), 162. doi:10.2903/j.efsa.2015.3991, 3991

EFSA Panel on Biological Hazards (BIOHAZ), 2011; Scientific opinion on Campylobacter in broiler meat production: control options and performance objectives and/or targets at different stages of the food chain. EFSA J., 9(4), 141 pp. doi:10.2903/j.efsa.2011.2105. Available online: www.efsa.europa.eu/efsajournal
EFSA Panel on Biological Hazards (BIOHAZ), 2010. Scientific opinion on quantification of the risk posed by broiler meat to human campylobacteriosis in the EU. EFSA Journal 8 (1437), 89.

Ellis-Iversen, J., Jorgensen, F., Bull, S., Powell, L., Cook, A.J., Humphrey, T.J., 2009. Risk factors for Campylobacter colonisation during rearing of broiler flocks in Great Britain. Prev. Vet. Med. 89, 178-184.

Guerin, M.T., Martin, W., Reiersen, J., Berke, O., McEwen, S.A., Bisaillon, J.-R., Lowman, R., 2007. A farm-level study of risk factors associated with the colonization of broiler flocks with Campylobacter spp. in Iceland, 2001-2004. Acta. Vet. Scand 49, 18.

Guerin, M.T., Martin, W., Reiersen, J., Berke, O., McEwen, S.A., Bisaillon, J.-R., Lowman, R., 2007. House-level risk factors associated with the colonization of broiler flocks with Campylobacter spp. in Iceland, 2001 - 2004. BMC Vet. Res. 3,1 .

Guerin, M.T., Martin, S.W., Reiersen, J., Berke, O., McEwen, S.A., McEwen, S.A., Bisaillon, J.-R., Lowman, R., Frioriksdottir, V., Berke, O., 2008. Temperature-related risk factors associated with the colonization of broiler-chicken flocks with Campylobacter spp. in Iceland, 2001-2004. Prev. Vet. Med. 86, 14-29.

Hald, B., Skovgård, H., Pedersen, K., Bunkenborg, H., 2008. Influxed insects as vectors for Campylobacter jejuni and Campylobacter coli in Danish broiler houses. Poult. Sci. 87, 1428-1434.

Hald, B., Sommer, H.M., Skovgard, H., 2007. Use of fly screens to reduce Campylobacter spp. introduction in broiler houses. Emerg. Infect. Dis. 13, 1951-1953.

Hald, B., Wedderkopp, A., Madsen, M., 2000. Thermophilic Campylobacter spp. in Danish broiler production: A cross-sectional survey and a retrospective analysis of risk factors for occurrence in broiler flocks. Avian Pathol 29, 123-131.

Hansson, I., Engvall, E.O., Vågsholm, I., Nyman, A., 2010. Risk factors associated with the presence of Campylobacter-positive broiler flocks in Sweden. Prev. Vet. Med. 96, 114-121.

Høg, B.B., Sommer, H.M., Larsen, L.S., Sørensen, A.I.V., David, B., Hofshagen, M., Rosenquist, H., 2016. Farm specific risk factors for Campylobacter colonisation in Danish and Norwegian broilers. Prev. Vet. Med. doi:10.1016/j.prevetmed.2016. 04.002 .

Høg, B.B., Rosenquist, H., Sørensen, A.I.V., Larsen, L.S., Osek, J., Wieczorek, K. Kusyk, P., Cerdà-Cuéllar, M., Dolz, R., Urdaneta, S., David, B., Hofshagen, M., Wagenaar, J.A., Bolder, N., Jørgensen, F., Williams, N., Merga, Y., Humphrey, T.. Questionnaire survey among broiler producers in six European countries.

ISO 10272-1, 2006. Microbiology of food and animal feeding stuffs - Horizontal method for detection and enumeration of Campylobacter spp. Part 1: Detection method.

Jonsson, M.E., Chriél, M., Norström, M., Hofshagen, M., 2012. Effect of climate and farm environment on Campylobacter spp. colonisation in Norwegian broiler flocks. Prev. Vet. Med. 107, 95-104.

Jore, S., Viljugrein, H., Brun, E., Heier, B.T., Borck, B., Ethelberg, S., Hakkinen, M., Kuusi, M., Reiersen, J., Hansson, I., Engvall, E.O., Løfdahl, M., Wagenaar, J.A., van Pelt, W., Hofshagen, M., 2010. Trends in Campylobacter incidence in broilers and humans in six European countries, 1997-2007. Prev. Vet. Med. 93, 33-41.

Klena, J.D., Parker, C.T., Knibb, K., Ibbitt, J.C., Devane, P.M., Horn, S.T., Miller, W.G., Konkel, M.E., 2004. Differentiation of Campylobacter coli, Campylobacter jejuni, Campylobacter lari, and Campylobacter upsaliensis by a multiplex PCR developed from the nucleotide sequence of the lipid A gene lpxA. Journal of Clinical Microbiology 42, 5549-5557.

Little, R.J.A., Rubin, D.B., 2002. Statistical Analysis with Missing Data. Wiley Series in Probability and Statistics, pp. 383-389.

Lund, M., Nordentoft, S., Pedersen, K., Madsen, M., 2004. Detection of Campylobacter spp. in chicken fecal samples by real-time PCR. J. Clin. Microbiol 42, 5125-5132.

Lyngstad, T.M., Jonsson, M.E., Hofshagen, M., Heier, B.T., 2008. Risk factors associated with the presence of Campylobacter species in Norwegian broiler flocks. Poult Sci. 87, 1987-1994.

Newell, D.G., Elvers, K.T., Dopfer, D., Hansson, I., Jones, P., 2011. Biosecurity-based interventions and strategies to reduce Campylobacter spp. on poultry farms. Appl. Environ. Microbiol. 77, 8605-8614.

Patrick, M.E., Christiansen, L.E., Wainø, M., Ethelberg, S., Madsen, H., Wegener, H.C. 2004. Effects of climate on incidence of Campylobacter spp. in humans and prevalence in broiler flocks in Denmark. Appl. Environ. Microbiol 70, 7474-7480.

Pigott, T.D., 2001. A review of methods for missing data. Educational Research and Evaluation 7, 353-383.

Rosenquist, H., Boysen, L., Galliano, C., Nordentoft, S., Ethelberg, S., Borck, B., 2009. Danish strategies to control Campylobacter in broilers and broiler meat: facts and effects. Epidemiol. Infect 137, 1742-1750.

Sommer, H.M., Heuer, O.E., Sørensen, A.I., Madsen, M., 2013. Analysis of factors important for the occurrence of Campylobacter in Danish broiler flocks. Prev. Vet Med. 111, 100-111.

Voss, D.S.Multicollinearity, 2004. Entry prepared for: encyclopedia of social measurement. Submitted: Feb. 20.

WHO, 2012. The global view of campylobacteriosis. Report of an expert consultation, Utrecht, Netherlands, 9-11 July 2012. http://www.who.int/iris/bitstream/10665 80751/1/9789241564601_eng.pdf 